\title{
THE INFLUENCE OF PARAMEDIC QUALIFICATION LEVEL ON THE ADMINISTRATION OF ANALGESIA IN THE PREHOSPITAL SETTING
}

\author{
Bill Lord $\mathrm{PhD}^{1^{\star}}$, Toby Keene MPH ${ }^{2,3}$, Cassie Luck BParamedicSc ${ }^{4}$
}

*wlord@aapt.net.au

\section{OPEN ACCESS ARTICLE}

Recommended Citation: Lord B, Keene T, Luck C. The influence of paramedic qualification level on the administration of analgesia in the prehospital setting. Irish Journal of Paramedicine. 4(2). Dec 2019. https://doi.org/10.32378/ ijp.v4i2.187

Received: 9 May 2019

Revised: 25 Jul 2019

Accepted: 9 Aug 2019

Published: 8 Sep 2019

Copyright: (๑) 2019, the authors. This is an Open Access article distributed under the terms of the Creative Commons Attribution-Non-CommercialShare Alike 4.0 International licence which permits use, distribution, and reproduction in any medium, provided the original work and any attributes thereof are properly cited, are distributed under the same licence, and that the work is not used for commercial purposes.

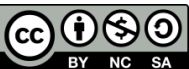

Funding/support: None declared.

Competing interests: None declared.

Provenance and review: Not commissioned, peer-reviewed.

\section{Author affiliations}

1. Monash University, Australia

2. ACT Ambulance Service, Australia

3. Australian National University, Australia

4. University of the Sunshine Coast, Australia

\section{Abstract}

\section{Background}

Under treatment of pain has been reported in the paramedic literature, and reasons for these disparities are not well understood.

\section{Aims}

As the qualification level of the paramedic may affect analgesia administration, the primary aim of this study was to determine the impact of paramedic qualification on the provision of any analgesia for patients reporting pain.

\section{Methods}

Retrospective study of de-identified patient care records from one Australian ambulance service over a period of 6 months. Inclusion criteria were age was > 17 years, initial pain severity score was $>3 / 10$ and Glasgow Coma Score $>13$. Paramedics in this setting can administer inhaled methoxyflurane, intravenous/ intramuscular morphine sulphate or intranasal fentanyl for pain depending on level of qualification - Ambulance Paramedic (AP) or Intensive Care Paramedic (ICP). Data were descriptively analysed for analgesia administration and type of analgesic by predictor variables: age, sex, pain score and case nature. Pearson's chi-square test was used to test for associations between the outcome of interest and predictor variables. Adjusted logged odds of patients receiving analgesia was tested with binomial logistic regression.

\section{Findings}

3173 patient records met the inclusion criteria. ICP treated $86 \%$ of the sample population. Of those treated by an AP, $76.2 \% \quad(n=340)$ received analgesia, whereas $71.6 \% \quad(n=1952)$ of patients treated by an ICP received analgesia $(p=0.042)$. Methoxyflurane was the most frequently administered analgesic, with $39.9 \%$ of the patients $(n=1,264)$ receiving this agent; $31.1 \%$ of patients $(n=988)$ received morphine, and $14.2 \% \quad(n=452)$ received fentanyl. The unadjusted regression model found that $\mathrm{AP}$ have higher odds of administering analgesia than ICP paramedics (OR 1.264, $p<0.05)$. However, once other covariates are included in the logistic regression, the significance no longer exists.

\section{Conclusion}

Paramedic qualification is not associated with the administration of analgesia in this setting. This study contributes to the gap in knowledge regarding disparities in analgesia for adults experiencing pain and may inform future research that aims to identify and reduce barriers to appropriate pain management in the paramedic practice setting.

Keywords: analgesia; pain management; paramedic; emergency medial service 


\section{Introduction}

Access to pain relief is considered a basic human right.(1) In addition to the humanitarian foundation for the management of pain, the early alleviation of acute pain has long term benefits that include a reduced odds of long term sequela such as chronic pain.(2) Pain is a frequently reported symptom in the paramedic practice setting, and as such the effective management of pain is an important component of practice. $(3,4)$ Pain relief has been identified as an important outcome measure for Emergency Medical Service (EMS) providers,(5) and evidence-based guidelines have been developed that addresses the importance of recognizing, assessing, and treating pain. $(6,7)$

Options for alleviating pain are typically prescribed by paramedic clinical practice guidelines, and although paramedic education, qualification and scope of practice will determine the range of analgesic options available, all paramedics providing emergency care in Australia are able to manage pain through pharmacological and nonpharmacological means. Despite this, the under-treatment or non-treatment of pain has been reported in the prehospital literature.(8) Factors affecting pain management span domains of knowledge, experience, communication, organizational aspects and attitudes, (9) with the latter including paramedics' suspicions of drug seeking as a reason for reporting pain. $(10,11)$ Patient factors may also affect a paramedic's decision to provide analgesia with one study finding women were less likely than men to receive analgesia for isolated limb injuries.(12) Despite this, causes of observed disparities in paramedic pain management practice remain poorly understood.

In Australia, the term paramedic refers to professional staff (as opposed to volunteers and first responders) employed to provide emergency health care by the statutory provider of Emergency Medical Services in each state and territory. There are also paramedic specializations such as critical care, intensive care and flight paramedic. The scope of practice for each is designed to deliver care to high acuity or special needs populations. As with other health professionals, paramedics provide varying degrees of clinical care according to their training and approved scope of practice. In Australia, paramedics have only been registered health professionals since December 2018. However, scope of practice is not determined by the national regulator but instead determined by their employer based on local governance practices.

Ambulance services in Australia generally attempt to triage requests for assistance such that higher levels of clinical practitioner see the most unwell patients. Thus, more highly qualified paramedics may be more likely to provide analgesia due to their increased exposure to high acuity patients. Although the level of certification and the experience of the paramedic may influence pain management decisions, there is limited evidence of the influence that scope of paramedic clinical practice has on pain management practice. A better understanding of how the different levels of paramedic practice influence the administration of analgesia will inform education and clinical practice. As such, the primary aim of this study was to determine the impact of paramedic scope of practice - referred to as "paramedic qualification" in this study - on the provision of analgesia for patients reporting pain, with a secondary aim the identification of patient and case type factors that may be associated with analgesia administration.

\section{Materials and methods}

\section{Study Design and Setting}

This retrospective study analysed de-identified electronic patient care records (ePCR) from the Australian Capital Territory Ambulance Service (ACTAS) over a period of 6 months spanning 1 July 2015 to 31 December 2015. The ACTAS is responsible for providing emergency and non-emergency ambulance services to members of the community throughout the Australian Capital Territory. During the 2014-15 financial year, the service responded to 35,478 emergency and urgent incidents in a region with a population of approximately 400,000.(13) Paramedics are employed as either Ambulance Paramedic (AP) or Intensive Care Paramedic (ICP). Each can administer inhaled methoxyflurane, intravenous/intramuscular (IV/IM) morphine sulphate or intranasal (IN) fentanyl for pain, with the ICP having the additional option of IV/IM ketamine. With the exception of ketamine, both qualification levels receive similar training on the use of 
analgesia. A summary of the recommended doses is shown in Table 1.

\begin{tabular}{|c|c|c|}
\hline Medication & Ambulance Paramedic & Intensive Care Paramedic \\
\hline Methoxyflurane & $\begin{array}{l}3 \mathrm{ml} \text { inhaled via inhaler } \\
1 \mathrm{x} \text { repeat as required }\end{array}$ & $\begin{array}{l}3 \mathrm{ml} \text { inhaled via inhaler } \\
1 \mathrm{x} \text { repeat as required }\end{array}$ \\
\hline $\begin{array}{l}\text { Morphine } \\
\text { sulphate }\end{array}$ & $\begin{array}{l}\text { IV: Up to } 0.05 \mathrm{mg} / \mathrm{kg} \mathrm{IV} \text {, over } \\
2 \text { minutes. May be repeated } \\
\text { at } 5 \text { minutes intervals, until } \\
\text { pain is managed. Up to a } \\
\text { maximum of } 15 \mathrm{mg} \\
\mathrm{IM}: 0.1 \mathrm{mg} / \mathrm{kg} \text {. Repeat once, } \\
\text { after } 30-45 \text { minutes, if re- } \\
\text { quired. } \\
\text { Up to a maximum of } 15 \mathrm{mg}\end{array}$ & $\begin{array}{l}\text { IV: Up to } 0.05 \mathrm{mg} / \mathrm{kg} \mathrm{IV} \text {, over } 2 \\
\text { minutes. May be repeated at } 5 \\
\text { minutes intervals, until pain is } \\
\text { managed. No dose limit. } \\
\text { IM: } 0.1 \mathrm{mg} / \mathrm{kg} \text {. Repeat once, } \\
\text { after } 30-45 \text { minutes, if re- } \\
\text { quired. } \\
\text { No dose limit. }\end{array}$ \\
\hline Fentanyl & $\begin{array}{l}\text { IN: } 30-180 \text { mcg, according to } \\
\text { patient weight. Repeat as } \\
\text { required every } 5-10 \text { minutes } \\
\text { until pain is managed. No } \\
\text { dose limit. }\end{array}$ & $\begin{array}{l}\text { IN: } 30-180 \mathrm{mcg} \text {, according to } \\
\text { patient weight. Repeat as re- } \\
\text { quired every } 5-10 \text { minutes until } \\
\text { pain is managed. No dose limit. }\end{array}$ \\
\hline Ketamine & Not administered & $\begin{array}{l}\text { IV: Up to } 1 \mathrm{mg} / \mathrm{kg} \text { in increments } \\
\text { of } 5-20 \mathrm{mg} \text { at intervals of } 30-60 \\
\text { seconds. Repeat as required. } \\
\text { No dose limit. } \\
\text { IM: } 0.5-1 \mathrm{mg} / \mathrm{kg} \text {. } \\
\text { No dose limit. }\end{array}$ \\
\hline
\end{tabular}

Table 1. Summary of the dosing regime authorized for use by each qualification level of paramedic during the study period.

\begin{tabular}{|c|c|c|c|c|c|}
\hline \multicolumn{5}{|c|}{$\begin{array}{c}\text { CMG } 2 \text { - PAIN MANAGEMENT } \\
\text { (Revised: March 2014) }\end{array}$} & 8 \\
\hline \multicolumn{6}{|c|}{ RELIEF OF PAIN AND SUFFERING IS A PRIME GOAL OF AMBULANCE CARE } \\
\hline \multicolumn{3}{|c|}{$\begin{array}{l}\text { Pain is what the patient says it is! } \\
\text { Always offer pain relief to the patient. }\end{array}$} & \multicolumn{3}{|c|}{$\begin{array}{l}\text { If possible, pharmacology should be directed at the apparent } \\
\text { underlying cause: }\end{array}$} \\
\hline \multirow{2}{*}{\multicolumn{3}{|c|}{$\begin{array}{l}\text { Pain assessment (PQRST) } \\
\text { Quantitate if possible (scale and description) } \\
\text { Document on case sheet }\end{array}$}} & ICP & GTN - sublingually for ischaemic chest pain & AP \\
\hline & & & ICP & $\begin{array}{c}\text { Methoxyflurane - mild to moderate pain; patients } \\
\text { unable to have narcotics; management of labour; } \\
\text { often best for paediatrics }\end{array}$ & AP \\
\hline \multicolumn{3}{|c|}{ Basic care is fundamental to pharmacological management: } & ICP & $\begin{array}{l}\text { Morphine - ischaemic chest pain and for all other } \\
\text { pain unless contraindicated }\end{array}$ & AP \\
\hline ICP & Reassurance & AP & \multirow{3}{*}{ ICP } & \multirow{3}{*}{$\begin{array}{l}\text { Fentanyl - moderate to severe pain; patients unable } \\
\text { to have morphine sulphate; } \\
\text { best for paediatrics - no IV required }\end{array}$} & \multirow{3}{*}{ AP } \\
\hline ICP & Posture & AP & & & \\
\hline ICP & Splinting & AP & & & \\
\hline ICP & Cooling of burns & AP & ICP & $\begin{array}{l}\text { Midazolam - small doses may be added to analgesia } \\
\text { for musculoskeletal pain }\end{array}$ & \\
\hline ICP & Occlusive dressings & AP & \multirow[t]{2}{*}{ ICP } & \multirow{2}{*}{$\begin{array}{l}\text { Ketamine - pain management in selected patients. } \\
\text { May be used with alternate small doses of morphine. }\end{array}$} & \\
\hline ICP & Control of temperature (especially the cold) & AP & & & \\
\hline \multirow[t]{2}{*}{ ICP } & Gentle handling & AP & & & \\
\hline & $\begin{array}{l}\text { ISCHAEMIC } \\
\text { ALL OTHER PAIN: }\end{array}$ & $\begin{array}{l}\text { ST PA } \\
\text { for cor }\end{array}$ & $\begin{array}{l}n \text { for a } \\
\text { f pain }\end{array}$ & $\begin{array}{l}\text { bolition of pain } \\
\text { to a comfortable level }\end{array}$ & \\
\hline
\end{tabular}

Figure 1. ACTAS pain management guideline in use during the study period. 
The administration of analgesia by ACTAS paramedics is governed by a clinical management guideline (see Figure 1 for the guideline in effect during the study period). Paramedics at both qualification levels are authorized to provide analgesia up to the recommended dosage without reference to online medical control. Repeat doses are authorized with the intent to reduce pain to a tolerable level, except for pain associated with Acute Coronary Syndrome (ACS) where the aim is to abolish the pain. Paramedics can administer any of the authorized analgesic agents, singly or in combination, based on their own judgement.

ACTAS paramedics respond to requests for service made via the emergency telephone system. The ACTAS call centre dispatches the closest ambulance using a computer aided dispatch system that tracks the location of ambulances using the global positioning system. The call centre dispatches the closest ambulance to the incident regardless of the qualification level of the attending paramedics. No attempt is made to match requests for service to the responding qualification level. This provides a degree of randomization in terms of the qualification level of the treating paramedic.

\section{Participants and Data Collected}

This study used a convenience contiguous dataset of all cases attended by ACTAS paramedics, with data de-identified and extracted by ACTAS from the electronic patient care record (ePCR) generated by the paramedics for each case attended during the study period. All patients aged 18 years or greater with a Glasgow Coma Score (GCS) of 14 or greater and where the initial pain severity score is greater than 3 were included in the dataset for analysis. The ePCR fields used in the analysis were the case date, treating paramedic's level of practice, pain severity score using an 11-point Verbal Numeric Rating Scale (VNRS; 0-10 and unable to rate), GCS, age (years), gender, cause of pain as recorded by the paramedic (medical or trauma), vital signs, and analgesia type and quantity administered. Cases involving transport from a hospital, non-transport or where analgesia had been administered prior to paramedic arrival were excluded. Case data fields were also searched for evidence of patient reported pain using the treating paramedic's notes in the history section of the ePCR. For cases that met inclusion criteria, the primary outcome measure was administration of any pharmacological analgesia, defined as any administration of methoxyflurane, morphine sulphate, fentanyl, ketamine or any combination of these agents.

\section{Ethical concerns}

Ethics approval was granted by the University of the Sunshine Coast Human Research Ethics Committee (E/16/054). Participant consent was not necessary as this study involves the use of an existing collection of data or records that contain only nonidentifiable data about human beings (i.e. data that have never been labelled with individual identifiers or from which identifiers have been permanently removed) in accordance with section 5.1.22 of the Australian Government National Statement on Ethical Conduct in Human Research (2007).

Outcomes of Interest

The primary outcome of interest was the administration of any analgesic to patients recorded as reporting pain. This outcome is a dichotomized version of the medication received variable. Responses were coded as $1=$ analgesic administered, and $0=$ no analgesic administered. Paramedic qualification was the key predictor of interest. Patient sex, age, initial pain score and case nature were included in the analysis as control variables.

\section{Statistical Analysis}

The data were descriptively analysed for analgesia administration and type of analgesic by predictor variables: age, sex, pain score and case nature. Pearson's chi-square test was used to test for associations between the outcome of interest and predictor variables. Following this, the adjusted logged odds of patients receiving analgesia was tested with binomial logistic regression using a stepped modelling approach. A baseline model was established with only paramedic qualification included. Each successive model added in another predictor variable to assess change in the outcome variable. Lastly, statistically 
significant models were tested using Likelihood Ratio test to ascertain the model of best fit. Stata version 14 (Stata Corporation, College Station, Texas) was used to undertake the statistical analysis.

\section{Results}

During the study period, 3173 patient records were identified that met the inclusion criteria (record of pain, age $\geq 18$, VNRS $\geq 4$, GCS $\geq 14$ ) that were treated and transported by either Ambulance Paramedic (AP) or Intensive Care Paramedic (ICP) (Figure 2). The demographic data for the 3173 cases is shown in Table 2.

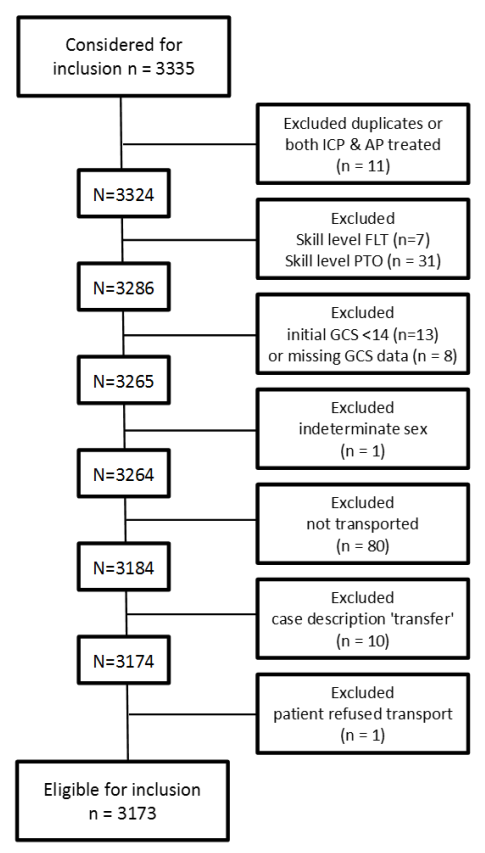

Figure 2: Excluded cases (FLT: Flight Paramedic; PTO: Patient Transport Officer)

\begin{tabular}{|c|c|c|c|c|}
\hline Category & Variable & $\mathbf{N}(\%)$ & Analgesic & $P$-value \\
\hline Sex & $\begin{array}{l}\text { Female } \\
\text { Male }\end{array}$ & $\begin{array}{l}1863(59 \%) \\
1310(41 \%)\end{array}$ & $\begin{array}{l}1335(72 \%) \\
957(73 \%)\end{array}$ & 0.388 \\
\hline Paramedic Qualification & $\begin{array}{l}\text { AP } \\
\text { ICP }\end{array}$ & $\begin{array}{c}446(14 \%) \\
2727(86 \%) \\
\end{array}$ & $\begin{array}{c}340(76.2 \%) \\
1952(71.6 \%) \\
\end{array}$ & 0.042 \\
\hline \multirow[t]{2}{*}{ Age (Yrs) } & \multirow{2}{*}{$\begin{array}{l}18-40 \\
41-60 \\
61-80 \\
81-100\end{array}$} & \multirow{2}{*}{$\begin{array}{l}1012(32 \%) \\
867(27 \%) \\
848(27 \%) \\
446(14 \%)\end{array}$} & \multirow{2}{*}{$\begin{array}{l}739(73 \%) \\
643(74 \%) \\
602(71 \%) \\
308(69 \%)\end{array}$} & 0.185 \\
\hline & & & & \\
\hline \multirow[t]{2}{*}{ Pain Score } & \multirow{2}{*}{$\begin{array}{l}\text { Moderate pain (VNRS 4-6) } \\
\text { Severe pain (VNRS } 7-10 \text { ) }\end{array}$} & \multirow{2}{*}{$\begin{array}{l}1814(57 \%) \\
1359(43 \%)\end{array}$} & \multirow{2}{*}{$\begin{array}{l}1087(60 \%) \\
1205(89 \%)\end{array}$} & $<0.001$ \\
\hline & & & & \\
\hline Case Nature & $\begin{array}{l}\text { Traumatic } \\
\text { Medical } \\
\text { Other }\end{array}$ & $\begin{array}{c}832(26 \%) \\
2291(72 \%) \\
50(2 \%)\end{array}$ & $\begin{array}{c}709(85 \%) \\
1556(68 \%) \\
27(61 \%)\end{array}$ & $<0.001$ \\
\hline Methoxyflurane use ${ }^{1}$ & $\begin{array}{l}\text { AP } \\
\mathrm{ICP}\end{array}$ & $\begin{array}{c}446(14 \%) \\
2727(86 \%)\end{array}$ & $\begin{array}{l}204(16 \%) \\
1060(84 \%)\end{array}$ & 0.006 \\
\hline Fentanyl use $^{1}$ & $\begin{array}{l}\text { AP } \\
\mathrm{ICP}\end{array}$ & $\begin{array}{c}446(14 \%) \\
2727(86 \%)\end{array}$ & $\begin{array}{c}78(17 \%) \\
374(83 \%)\end{array}$ & 0.035 \\
\hline \multirow[t]{2}{*}{ Morphine use $^{1}$} & AP & $446(14 \%)$ & $144(15 \%)$ & 0.572 \\
\hline & $\mathrm{ICP}$ & $2727(86 \%)$ & $844(85 \%)$ & \\
\hline
\end{tabular}

Table 2: Sample Population Characteristics ( $\mathrm{n}$, column by percent) by analgesic administration ( $\mathrm{n}$, row percent with chi-square characteristic). Note: 1 Some patients received more than one analgesic agent. 
ICP treated $86 \%$ of the sample population. Moderate pain of 3-6 VNRS was reported in $57 \%$ of all cases and $74 \%$ of all cases had non-traumatic pain (Table 2 ). In total, $72 \%$ $(n=2292)$ of the sample received analgesia from the treating paramedic. Of those treated by an AP, $76.2 \%(n=340)$ received analgesia, and $71.6 \%(n=1952)$ of patients treated by an ICP received analgesia. Table 2 presents a statistically significant association between paramedic qualification level and analgesic administration $(\mathrm{p}<0.05)$. Patient sex was not associated with analgesia administration $(\mathrm{p}=0.388)$. Patients in severe pain (VNRS 7 -10) received analgesia in $89 \%$ of cases, as compared to $60 \%$ of patients reporting moderate pain (Table 2). This association was found to be statistically significant $(p<0.001)$, indicating an association between analgesic administration based on the initial pain score. Traumatic case nature was also found to be statistically significantly associated with analgesic administration $(\mathrm{p}<0.001)$.

The unadjusted regression model found that AP have higher odds ratio (OR) of administering analgesia than ICP paramedics (OR 1.264, $\mathrm{p}<0.05)$. However, once other covariates are included in the logistic regression, the significance no longer exists. When adding the variables of sex and age, the Pseudo R-squared does not change significantly, indicating no change in the overall goodness of fit of the model in explaining variation in the dependent variable- analgesia administration. With the addition of pain severity category to the model using moderate pain as the base (comparison) category, the odds ratio suggests that patients in severe pain have highly statistically significant larger odds of receiving analgesia than patients in moderate pain (OR 5.219, $\mathrm{p}<0.001$ ).

\begin{tabular}{|l|c|c|c|}
\hline Variable & OR & $95 \% \mathrm{Cl}$ & P Value \\
\hline Skill Level & & & \\
\hline ICP & $1.00^{*}$ & & \\
\hline AP & 1.153 & $0.90-1.49$ & 0.243 \\
\hline Sex & & & \\
\hline Male & $1.00^{*}$ & & 0.139 \\
\hline Female & 0.884 & $0.74-1.04$ & \\
\hline Age category(years) & & & 0.863 \\
\hline $18-40$ & $1.00^{*}$ & & 0.460 \\
\hline $41-60$ & 1.016 & $0.82-1.27$ & 0.255 \\
\hline $61-80$ & 0.920 & $0.74-1.15$ & \\
\hline $81-100$ & 0.856 & $0.66-1.12$ & \\
\hline Initial Pain Score category & & & \\
\hline moderate pain & $1.00^{*}$ & & $\mathbf{0 0 1}$ \\
\hline severe pain & $\mathbf{5 . 5 5 9}$ & $4.57-6.76$ & \\
\hline Case Nature & & & 0.001 \\
\hline Medical case & $1.00^{*}$ & & \\
\hline traumatic case & $\mathbf{3 . 1 6 8}$ & $2.54-3.95$ & \\
\hline other case & 0.751 & $0.389-1.45$ & \\
\hline Observations & 3173 & & \\
\hline Pseudo $R^{2}$ & 0.126 & & \\
\hline
\end{tabular}

* Referent: multivariate model included skill level, sex, age, initial pain score and case nature.

Table 3: Multivariate analysis of characteristics significantly associated with receiving analgesia

Lastly, case nature was added in the regression model, with trauma and other case types compared with medical cases. The odds ratio indicates that patients with case type coded as trauma have highly statistically significant larger odds of receiving analgesia than medical case patients (OR 3.142, $\mathrm{p}<0.001$ ). The exponentiated coefficient for severe pain increased in this model, suggesting a correlation between case nature and pain level. Overall, the regression analysis found that both pain severity and case nature explain variation in analgesic administration, more so than paramedic qualification level.

Methoxyflurane was the most frequently administered analgesic, with $39.9 \%$ of the patients $(n=1,264)$ receiving this agent; $31.1 \%$ of patients $(n=988)$ received morphine, and $14.2 \%(n=452)$ received fentanyl. Ketamine was administered to $1 \%(n=33)$. There was no statistical difference in administration of analgesic by clinical level, with the exception of methoxyflurane where AP were more likely to administer this agent 
$(\mathrm{p}<0.01)$. This difference remained when controlling for patient sex, age, initial pain severity score and case nature, which showed an adjusted odds ratio of 1.30 for methoxyflurane administration by AP (95\% CI 1.05-1.60). Table 3 shows the multivariate analysis of variables associated with the odds of receiving analgesia.

\section{Discussion}

Pain management is an important component of care provided by paramedics. Despite the availability of evidence-based guidelines, pain has been shown to be under assessed and undertreated.(14-19) Several predictors of disparity in the provision of analgesia by paramedics have been described, including sex and age.(20, 21) However, there is scant evidence of the effect of paramedic qualification level on analgesic administration in a setting where paramedics at all levels of qualification can provide pharmacological management of pain. This study aimed to determine whether the practice level of the paramedic was associated in differences in the frequency of analgesia administration. Although the ICP is an advanced level of practitioner with a higher level of education and training, and with access to an extended scope of practice including additional analgesic option, this advanced scope of practice was not associated with differences in analgesia for patients with moderate to severe pain.

Patients with severe pain (a VNRS greater than 7/10) were more likely to receive analgesia as were those with pain that was coded by the paramedic as traumatic in origin. The latter requires further investigation to explain this difference. However, disparities in analgesic administration by patient gender that has been described in previous studies were not found in this study. $(12,20)$ This study also failed to find an effect of patient age on odds of analgesic administration.

This study found that the majority of patients reporting moderate to severe pain received analgesia, and this is in contrast with other studies that show frequency of analgesia administration by paramedics.(16, 19, 22) This may reflect the importance placed on the assessment and early management of pain by the ambulance service and/or the clinical capabilities of paramedics employed by this agency. The effect of organizational or cultural influences on pain management may be a useful line on inquiry.

While our results are encouraging compared to other studies, overall only $72 \%$ of patients reporting pain overall and only $60 \%$ of patients reporting moderate pain received any analgesia. The difference between pharmacological management of moderate versus severe pain may be explained by the pharmaceutical agents the paramedics had to choose from. Current guidelines advocate the use of paracetamol and/or non-steroidal antiinflammatory drugs for moderate pain rather than opioids. However, paramedic practice guidelines may not include these agents, and paramedics may be reluctant to administer parenteral opioids to patients with moderate pain. Other possibilities include situational factors such as distance to hospital and undocumented patient refusal of analgesics. The current study did not attempt to address these factors, and further research should consider this.

\section{Limitations}

This study has some limitations that should be considered when interpreting the results. Errors in the documentation of care cannot be identified in this retrospective study of patient care records. The study involved data from a single Australian ambulance service and as such this may limit the generalizability of the results. Paramedics in this study setting generally work in pairs with either the same skill set or a mix of the skill sets that were included in this study.

Although the qualification level of the treating paramedic was extracted for analysis, the interactions between crew members may have influenced decisions to treat. This possibility was not studied. The study was also unable to control for the effect of any non-pharmacological methods that may have been used to alleviate pain. In addition, the temporal nature of the pain could not be determined from the available data, and as such it is not possible to differentiate acute and chronic pain. The study only considered initial reported pain score, not final score. As such, it is unable to comment on the effectiveness of analgesia received by patients. 


\section{Conclusion}

Paramedic qualification is not associated with the administration of analgesia in this prehospital setting. This study contributes to the gap in paramedic science literature on paramedic qualification and administration of analgesia in the prehospital setting regarding factors associated with analgesia administration and may inform future research that aims to identify and reduce barriers to appropriate pain management in the paramedic practice setting.

\section{Acknowledgements}

The authors acknowledge the support of the ACT Ambulance Service in providing the data for this study and the statistical support provided by Dr Rebecca Coates.

\section{References}

1. Cousins MJ, Lynch ME. The Declaration Montreal: access to pain management is a fundamental human right. Pain. 2011;152(12):2673-4.

2. Clay FJ, Watson WL, Newstead SV, McClure RJ. A systematic review of early prognostic factors for persistent pain following acute orthopedic trauma. Pain Res Manag. 2012;17(1).

3. Galinski M, Ruscev M, Gonzalez G, Kavas J, Ameur L, Biens D, et al. Prevalence and management of acute pain in prehospital emergency medicine. Prehosp Emerg Care. 2010;14(3):334-9.

4. Lord B, Woollard M. The reliability of vital signs in estimating pain severity among adult patients treated by paramedics. Emerg Med J. 2011;28(2):147-50.

5. Coster JE, Irving AD, Turner JK, Phung VH, Siriwardena AN. Prioritizing novel and existing ambulance performance measures through expert and lay consensus: A three-stage multimethod consensus study. Health Expect. 2017;00:1-12.

6. Brown KM, Hirshon JM, Alcorta R, Weik TS, Lawner B, Ho S, et al. The Implementation and Evaluation of an Evidence-based Statewide Prehospital Pain Management Protocol Developed using the National Prehospital Evidence-based Guideline Model Process for Emergency Medical Services. Prehospital Emergency Care. 2014;18(Supplement 1):45-51.

7. Gausche-Hill M, Brown KM, Oliver ZJ, Sasson C, Dayan PS, Eschmann NM, et al. An evidence-based guideline for prehospital analgesia in trauma. Prehosp Emerg Care. 2014;18(Supp 1):25-34.

8. Haley KB, Lerner EB, Guse CE, Pirrallo RG. Effect of system-wide interventions on the assessment and treatment of pain by emergency medical services providers. Prehosp Emerg Care. 2016;20(6):752-8.

9. Berben S, Meijs T, van Grunsven P, Schoonhoven L, van Achterberg T. Facilitators and barriers in pain management for trauma patients in the chain of emergency care. Injury. 2012;43(9):1397-402.

10. Hennes H, Kim MK, Pirrallo RG. Prehospital pain management: a comparison of providers' perceptions and practices. Prehosp Emerg Care. 2005;9(1):32-9.

11. Walsh B, Cone DC, Meyer EM, Larkin GL. Paramedic attitudes regarding prehospital analgesia. Prehosp Emerg Care. 2013;17(1):78-87.

12. Michael GE, Sporer KA, Youngblood GM. Women are less likely than men to receive prehospital analgesia for isolated extremity injuries. Am J Emerg Med. 2007;25(8):901-6.

13. Steering Committee for the Review of Government Service Provision. Report on Government Services: Emergency management Canberra: Productivity Commission; 2016 [6 November 2017]. Available from: http://www.pc.gov.au/ research/ongoing/report-on-government-services/2016/emergency-management.

14. Albrecht E, Taffe P, Yersin B, Schoettker P, Decosterd I, Hugli O. Undertreatment of acute pain (oligoanalgesia) and medical practice variation in prehospital analgesia of adult trauma patients: a $10 \mathrm{yr}$ retrospective study. British Journal of Anaesthesia. 2012 October 11, 2012.

15. Alonso-Serra HM, Wesley K, for the National Association of EMS Physicians Standards and Clinical Practices Committee. Position paper: prehospital pain management. Prehosp Emerg Care. 2003;7(4):482-8.

16. Jennings PA, Cameron P, Bernard S. Epidemiology of prehospital pain: an 
opportunity for improvement. Emerg Med J. 2011 June 1, 2011;28(6):530-1.

17. Luger TJ, Lederer W, Gassner M, Lockinger A, Ulmer H, Lorenz IH. Acute pain is underassessed in out-of-hospital emergencies. Acad Emerg Med. 2003;10 (6):627-32.

18. Matthews R, McCaul M, Smith W. A description of pharmacological analgesia administration by public sector advanced life support paramedics in the City of Cape Town. Afr J Emerg Med. 2017;7(1):24-9.

19. Siriwardena AN, Asghar Z, Lord B, Pocock H, Phung V-H, Foster T, et al. Patient and clinician factors associated with prehospital pain treatment and outcomes: cross sectional study. Am J Emerg Med. 2019;37(2):266-71.

20. Lord B, Cui J, Kelly AM. The impact of patient sex on paramedic pain management in the prehospital setting. Am J Emerg Med. 2009;27(5):525-9.

21. Platts-Mills TF, Hunold KM, Weaver MA, Dickey RM, Fernandez AR, Fillingim $\mathrm{RB}$, et al. Pain treatment for older adults during prehospital emergency care: variations by patient gender and pain severity. J Pain. 2013;14(9):966-74.

22. Lord B, Parsell B. Measurement of pain in the prehospital setting using a visual analogue scale. Prehosp Disaster Med. 2003;18(4):353-8. 